Revista Destaques Acadêmicos, Lajeado, v. 13, n. 2, 2021. ISSN 2176-3070

DOI: http://dx.doi.org/10.22410/issn.2176-3070.v13i2a2021.2945

http://www.univates.br/revistas

\title{
CONHECIMENTOS EMPÍRICOS SOBRE ASTRONOMIA DA COMUNIDADE INDÍGENA KANELA DO ARAGUAIA DA ALDEIA NOVA PUKANU
}

\author{
Gabriel Alves Tolentino', Devacir Vaz de Moraes², \\ Ana Claudia Tasinaffo Alves ${ }^{3}$
}

\begin{abstract}
Resumo: O ensino de Astronomia no Ensino Médio tende a proporcionar a formação de um estudante crítico e pleno, que estará preparado para interagir com a sociedade. Assim, a contribuição da Ciência se encontra atrelada à compreensão de outras culturas, como a dos indígenas. Nesse contexto, o presente texto é resultado de um estudo que objetivou analisar os conhecimentos sobre Astronomia da comunidade Kanela do Araguaia da Aldeia Nova Pukanu, no segundo semestre de 2019, por meio de uma pesquisa com enfoque qualitativo. A coleta de dados foi realizada por meio de pesquisa de campo com questionário, contendo oito perguntas abertas, tendo como sujeitos 35 indígenas da comunidade local, que aceitaram participar, voluntariamente, da investigação. Entre as estrelas mais citadas por eles estão: Estrela D'alva (35 participantes), Sol (35 participantes) e Estrela Cadente (35 participantes), já as constelações que mais vezes apareceram nas respostas foram: Constelações Cruzeiro do Sul (32 participantes), Caminho de Santiago (31 participantes), e Três Marias (31 participantes). Assim como em outros estudos, as estrelas e as constelações mais citadas pelos indígenas são as da Via Láctea. Ao analisar os resultados se percebeu que a comunidade utiliza os conhecimentos empíricos de Astronomia para se orientar e guiar em tarefas simples, cotidianas, que vão desde o preparo de um medicamento, caça, pesca e plantio até a colheita de produtos que são necessários para a sua subsistência.
\end{abstract}

Palavras-chave: Astronomia; Cultura Indígena; Ensino de Física.

1 Graduado em Física pelo IFMT Campus Confresa.

2 Mestre em Ensino de Física (UFMT), professor do IFMT Campus Confresa.

3 Doutora em Educação em Ciências e Matemática (REAMEC), professora do IFMT Campus Rondonópolis. 


\section{INTRODUÇÃO}

A Astronomia é considerada uma Ciência que estuda os corpos celestes, bem como a formação e o desenvolvimento do Universo (SANZOVO; BALESTRA, 2015). Muitas vezes, o ensino de Astronomia no Ensino Médio é feito de maneira superficial, no entanto, entende-se que é preciso que seja estudada de maneira mais aprofundada, para que seja possível os estudantes mobilizarem conhecimentos específicos da Astronomia. Para Housome (2010, p. 190): "o ensino de astronomia no Brasil ganha uma nova perspectiva na educação básica por meio da LBD/1996, consolidada pelos Parâmetros Curriculares Nacionais (PCN)".

Estudar Astronomia é importante para ampliar os conhecimentos de como é constituído o Universo, e seu conhecimento pode ser um estímulo para reflexões sobre o passado e o futuro dos humanos no Universo "não só por dimensionar o problema da localização espacial no cosmos, mas também por levantar questionamentos sobre as possibilidades de permanência num universo dinâmico e em expansão" (LAGO et al., 2018, p. 3).

Apesar da importância de estar presente nos currículos escolares, o ensino de Astronomia no Brasil ocorre, principalmente, em espaços não formais de ensino, em meios de divulgação, como: jornais, artigos científicos, planetários, programas de televisão, museus de ciência, observatórios, entre outros (LANGHI; NARDI, 2009).

Na Base Nacional Comum Curricular (BNCC), o estudo de "astronomia e cultura" é indicado já no $9^{\circ}$ ano do Ensino Fundamental, na temática "Terra e Universo". Para o Ensino Médio, o texto da BNCC orienta que o tema Astronomia seja trabalhado no itinerário formativo Ciências da Natureza e aparece como um conhecimento para se atingir a competência específica (número 2), que tem como foco "analisar e utilizar interpretações sobre a dinâmica da Vida, da Terra e do Cosmos para elaborar argumentos, realizar previsões sobre o funcionamento e a evolução dos seres vivos e do Universo, e fundamentar e defender decisões éticas e responsáveis" (BRASIL, 2018, p. 556).

Ao contrário da Astronomia convencional, uma Ciência Exata e essencialmente teórica, a Astronomia indígena utiliza métodos empíricos, relacionando o movimento do Sol, da Lua e das constelações com eventos meteorológicos que acontecem ao longo do ano, com períodos de chuva e de estiagem, de calor ou de frio. Com esse conhecimento, os povos indígenas constroem seus calendários, marcando a época dos trabalhos agrícolas, de floração e de frutificação, de reprodução dos peixes e outros animais (MARIUZZO, 2012).

Assim, as comunidades indígenas utilizam, frequentemente, a Astronomia para a sobrevivência, ou seja, usam no dia a dia como na pesca, na caça, no plantio, na colheita, na retirada de madeira e palha, entre outras atividades. A maioria dos conhecimentos astronômicos, por exemplo, dos 
indígenas é repassada de geração em geração, por meio de seus mitos, sendo de difícil compreensão pelos não indígenas (AFONSO, 2010).

A diversidade cultural entre os povos indígenas do Brasil é produto das características particulares de cada povo, expressas nas artes, na música, na medicina, nas tradições e rituais dos povos indígenas. Por meio da língua é possível conhecer a cultura dos povos, experiências e desafios vividos ao longo do tempo. "As línguas expressam também essa rica diversidade, porque essas representam modos distintos de classificar e compreender o mundo. São transmitidas de geração em geração por meio da tradição oral" (AMORIM; PALADINO, 2012, p. 128).

É comum verificar que cada povo sempre teve uma atenção em observar o céu noturno, cada um desses pode interpretar, de forma diferente, de acordo com o contexto que vive, com suas crenças, costumes e valores (ARAUJO, 2017). Embora não seja muito presente nos currículos escolares, a Astronomia faz parte do cotidiano dos indígenas. O conhecimento de Astronomia dos indígenas é passado de geração para geração, em espaços não-formais de aprendizagem, como ocorre também, muitas vezes, com os não-indígenas.

Os povos indígenas conhecem muito o ambiente que vive e tudo ao seu entorno, como plantas e animais, sendo comum também que eles utilizem seus conhecimentos e associem, por exemplo, as estações do ano e as fases da Lua com o clima e fauna e flora ao seu redor, como por exemplo os tupis-guaranis. "Para eles, cada elemento da Natureza tem um espírito protetor. As ervas medicinais são preparadas obedecendo a um calendário anual bem rigoroso" (AFONSO, 2006, p. 49). Indígenas brasileiros utilizando de seus conhecimentos próprios de Astronomia "definiam o tempo de colheita, a contagem de dias, meses e anos, a duração das marés, a chegada das chuvas. Desenhavam no céu histórias de mitos, lendas e seus códigos morais, fazendo do firmamento esteio de seu cotidiano" (AFONSO, 2006, p. 46).

Muitas são as relações com astros, constelações e estrelas. Em um estudo com indígenas da etnia Guarani MBYÁ, chamada de Nhu Porá, localizada no município de Torres, no Estado do Rio Grande do Sul, verificou-se que a comunidade explica as diferentes fases da Lua afirmando que essa possui uma espécie de ciclo vital como se a Lua tivesse "que nascer, crescer e desaparecer; sendo assim, cada fase da Lua faz parte desse ciclo, onde o astro renasce" (GARCIA et al., 2016, p. 21).

O conhecimento sobre o sistema astronômico indígena pela comunidade científica brasileira ainda é muito incipiente e informações preciosas podem se perder em espaço de tempo pequeno de uma ou duas gerações. A perda pode ocorrer "pelo rápido processo de globalização e pelas dificuldades em documentar, avaliar, validar, proteger e disseminar os conhecimentos dos índios brasileiros" (AFONSO, 2013, p. 2). 
Diante da relevância do tema apresentado, o presente estudo objetivou verificar quais os conhecimentos empíricos que a comunidade indígena Kanela do Araguaia, da aldeia Nova Pukanu, possui sobre Astronomia, como e quando eles o utilizam. A área em estudo é formada por mata e áreas alagadas, no entanto, a comunidade ainda conta com os recursos adquiridos ao longo dos tempos, sendo um desses os conhecimentos empíricos. Esses conhecimentos empíricos permanecem no cotidiano desta comunidade, de forma cultural, passando de geração em geração.

Os povos indígenas da Etnia Kanela do Araguaia - MT são remanescentes e reconhecidos por seus parentes da Etnia Kanela Apãniekrá, da Aldeia de Porquinhos, situada nos Municípios de Fernando Falcão e Grajaú, no Estado do Maranhão, e reconhecidos pelo Estado Brasileiro, conforme determina a Convenção 169 da Organização Internacional do Trabalho - OIT (BRASIL, 2004) e ratificada pela Presidência da República em 2006.

Oriundos da Aldeia Morro do Chapéu, atualmente, estão reivindicando um território, em áreas da União, situado no município de Luciara-MT. Segundo estes povos, eles carregam as marcas de um passado excludente, sonham com um país mais justo, no qual o direito de alguns não exclua o direito de outros, principalmente, dos menos favorecidos (NORA et al., 2020).

Hoje, a comunidade indígena Kanela do Araguaia tem, aproximadamente, 750 pessoas, e na aldeia Nova Pukanu, entre crianças e adultos, são aproximadamente 250 pessoas. A comunidade contou com o apoio da Escola Estadual Sol Nascente, que proporcionou salas anexas para os estudantes da comunidade, em que foram formadas quatro turmas, entre Ensino Fundamental, Ensino Médio e EJA.

Por meio das observações sobre a localidade da aldeia Nova Pukanu se pode notar a dificuldade que a comunidade encontra para ter acesso à cidade mais próxima. A comunidade ainda enfrenta outras dificuldades, como são poucas as pessoas aposentadas, a renda familiar é pequena, e para superar a falta de recursos, eles precisam caçar, pescar e plantar, e para se obter uma boa produtividade, o povo Kanela usa os conhecimentos empíricos sobre Astronomia, adquiridos ao longo dos anos.

\section{PERCURSO METODOLÓGICO}

A pesquisa foi caracterizada como qualitativa, em que o pesquisador precisa procurar "penetrar nas ideias, mentalidade, valores e intenções do produtor da comunicação para compreender sua mensagem". Dessa forma, as respostas, as palavras e os temas que são ditos pelos sujeitos junto com os dados do autor darão significado, mostrando intencionalidade, ideologias e percepções que condicionaram a mensagem de quem respondeu (CHIZZOTTI, 2006, p. 116). 
O presente estudo foi desenvolvido na comunidade indígena Kanela do Araguaia, na aldeia Nova Pukanu, localizada no município de Luciara-MT, encontrando-se a $90 \mathrm{~km}$ de distância da sede do município. A cidade mais próxima da aldeia é Porto Alegre do Norte, em uma distância de $50 \mathrm{~km}$, sendo o ponto de referência comercial, em função de ser mais perto e ter as melhores estradas.

A dificuldade de locomoção e o acesso à cidade em decorrência do transporte e distância ou mesmo a renda familiar contribuem para que as famílias adquiram e façam o uso dos conhecimentos empíricos, que são passados de geração para geração.

Os dados foram coletados, de forma presencial, para a realização da entrevista, o primeiro autor visitou a aldeia e por meio de questionário, contendo perguntas abertas foi conversando e anotando as respostas dos indígenas da comunidade local, que concordaram em participar, voluntariamente, da investigação, contribuindo com conhecimentos empíricos utilizados pela aldeia Nova Pukanu.

Foram coletadas as informações pessoais de cada participante da entrevista, como idade e gênero. Os sujeitos assinaram o Termo de Consentimento Livre e Esclarecido e não serão divulgados os seus nomes nos resultados da pesquisa, a fim de manter o anonimato.

O questionário foi composto pelas seguintes questões: 1) Já ouviu falar em Astronomia? 2) Você conhece alguma constelação? Se sim, quais são essas? 3) Você conhece alguma estrela? Se sim, qual é o nome dela? 4) Você sabe o nome da maior estrela já descoberta? 5) Qual é a estrela mais próxima da Terra? 6) Utiliza Astronomia em seu cotidiano? Se sim, em quais áreas? 7) O ciclo lunar influencia em algumas tarefas do seu cotidiano? 8) Como você avaliaria seu nível de conhecimento sobre os fenômenos astronômicos?

A importância da prática dos conhecimentos empíricos apresenta ponto de vista das pessoas da comunidade, e para que esses conhecimentos possam ser repassados para as gerações futuras, e possam ser utilizados no processo de sobrevivência. A sistematização dos dados obtidos foi apresentada por meio de quadros e de gráficos, de acordo com a frequência das respostas e essas foram analisadas de acordo com o referencial teórico estudado, conforme se apresenta na próxima seção.

\section{RESULTADOS E DISCUSSÕES}

Foram 35 indígenas da etnia Kanela do Araguaia, moradores da aldeia Nova Pukanu, que se propuseram responder às perguntas, possibilitando, assim, analisar os conhecimentos dos mesmos sobre Astronomia. A primeira pergunta buscou caracterizar os sujeitos da pesquisa por idade. Os investigados possuem idade entre 20 a 92 anos, como é possível observar no Quadro 1. 
Quadro 1 - Faixa etária dos sujeitos da pesquisa.

\begin{tabular}{|c|c|}
\hline Faixa etária & Número de entrevistados \\
\hline $20-40$ anos & 11 \\
\hline $41-60$ anos & 10 \\
\hline $61-80$ anos & 11 \\
\hline $81-92$ anos & 3 \\
\hline
\end{tabular}

Fonte: dados da pesquisa (2019).

Com a análise dos dados sobre a faixa etária, juntamente com a análise das respostas das demais questões, foi possível perceber que o conhecimento sobre a Astronomia foi passado entre as gerações, representando uma perpetuação dos conhecimentos e costumes da própria comunidade.

Por meio dos dados relacionados com a idade se perguntou para cada participante o gênero, sendo 19 do gênero masculino e 16 do gênero feminino. Sendo assim, a maioria dos entrevistados é de homens indígenas, mas com uma participação significativa das mulheres da aldeia.

A visão dos integrantes da aldeia Nova Pukanu, da etnia Kanela, acerca da Astronomia ficou evidenciada nas questões mais específicas relacionadas ao objeto de estudo. A terceira pergunta do questionário direcionada aos sujeitos envolvia identificar se já havia ouvido falar em Astronomia. Para esta questão, todos os participantes responderam que "sim", evidenciando-se novamente que o conhecimento sobre a Astronomia é um ato passado de geração para geração, o que corrobora com os autores Amorim e Paladino (2012).

Ao serem questionados sobre o conhecimento de alguma constelação, todos também responderam conhecer, para os integrantes da comunidade, conhecer as constelações é fator comum. Diante da pergunta sobre o conhecimento de alguma constelação, outra pergunta foi realizada: "quais constelações conhece?" A Figura 1 apresenta as constelações citadas pelos entrevistados, sendo que eles poderiam responder quantas lembrassem. 
Figura 1: Constelações citadas pelos entrevistados.

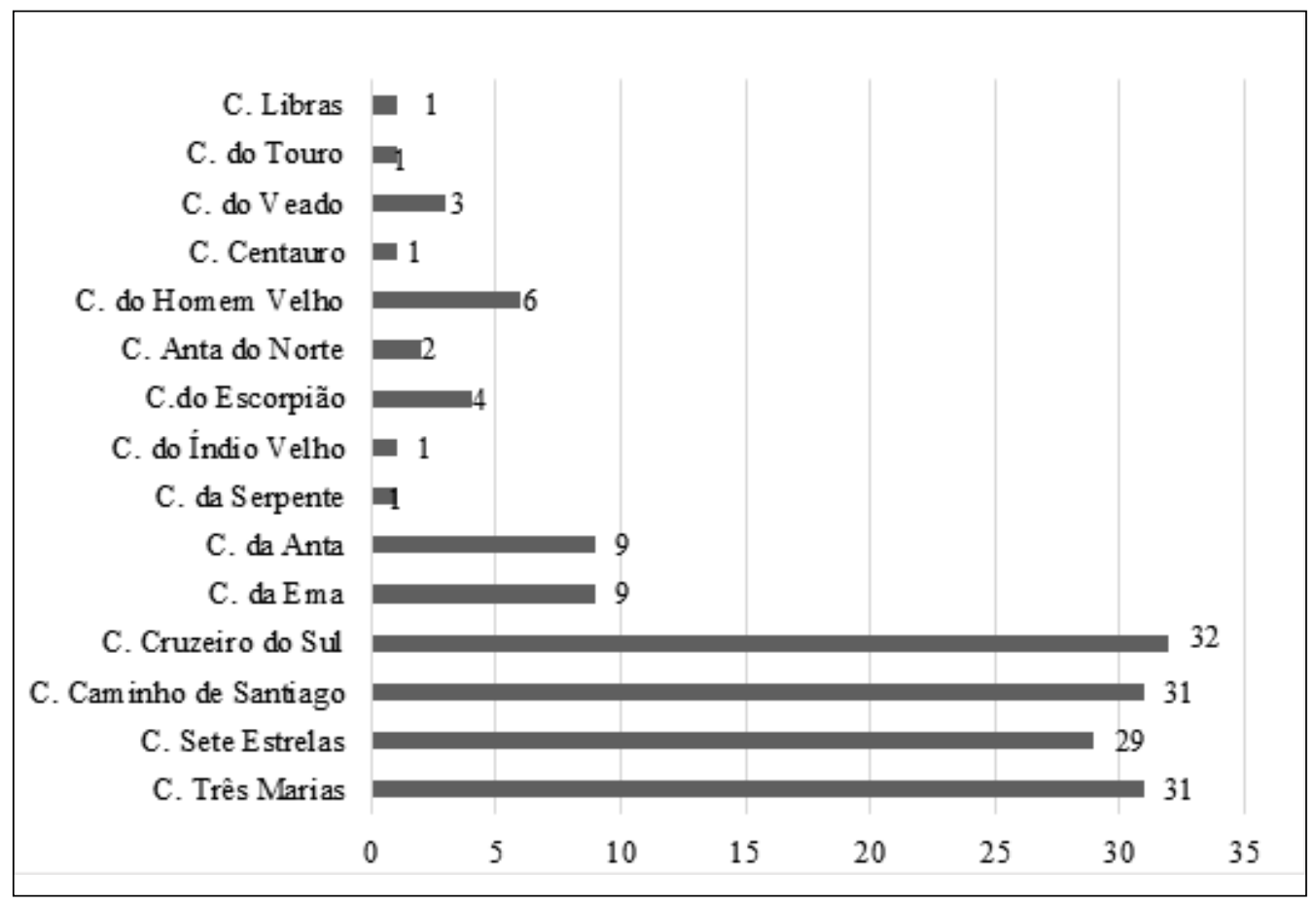

Fonte: dados da pesquisa (2019).

As constelações mais citadas pelos entrevistados foram as Constelações Cruzeiro do Sul (32 participantes), Caminho de Santiago (31 participantes), e Três Marias (31 participantes). As constelações menos citadas foram: Libras (1 participante); Touro (1 participante); Centauro (1 participante); Índio Velho (1 participante); Serpente (1 participante). Observa-se que apesar da constelação Cruzeiro do Sul ou Crux, como também é chamada, ser a menor das constelações, essa foi a mais citada.

Os indígenas do Brasil sempre consideraram as constelações da Via Láctea como as mais importantes, uma vez que para muitas etnias essa é chamada de Caminho da Anta (Tapi'i rapé, em guarani), também consideram estrelas individuais e de nebulosas, sobretudo, as escuras (AFONSO, 2013). Pelas respostas dos indígenas, que participaram do estudo, se verifica que as constelações citadas são também as da Via Láctea. As constelações mais conhecidas, pelos povos indígenas brasileiros, são: Constelação da Ema, Constelação do Homem Velho, Constelação da Anta do Norte e Constelação do Veado (AFONSO, 2013), sendo que as quatro também foram citadas pelos Kanela do Araguaia.

Para os entrevistados, o conhecimento das constelações mencionadas possibilita que eles se orientem para as direções que pretendem seguir. 
Com o questionamento sobre as constelações, foi perguntado qual estrela os entrevistados conhecem, o resultado obtido pelo questionamento está representado pela Figura 2.

Figura 2: Estrelas citadas na entrevista.

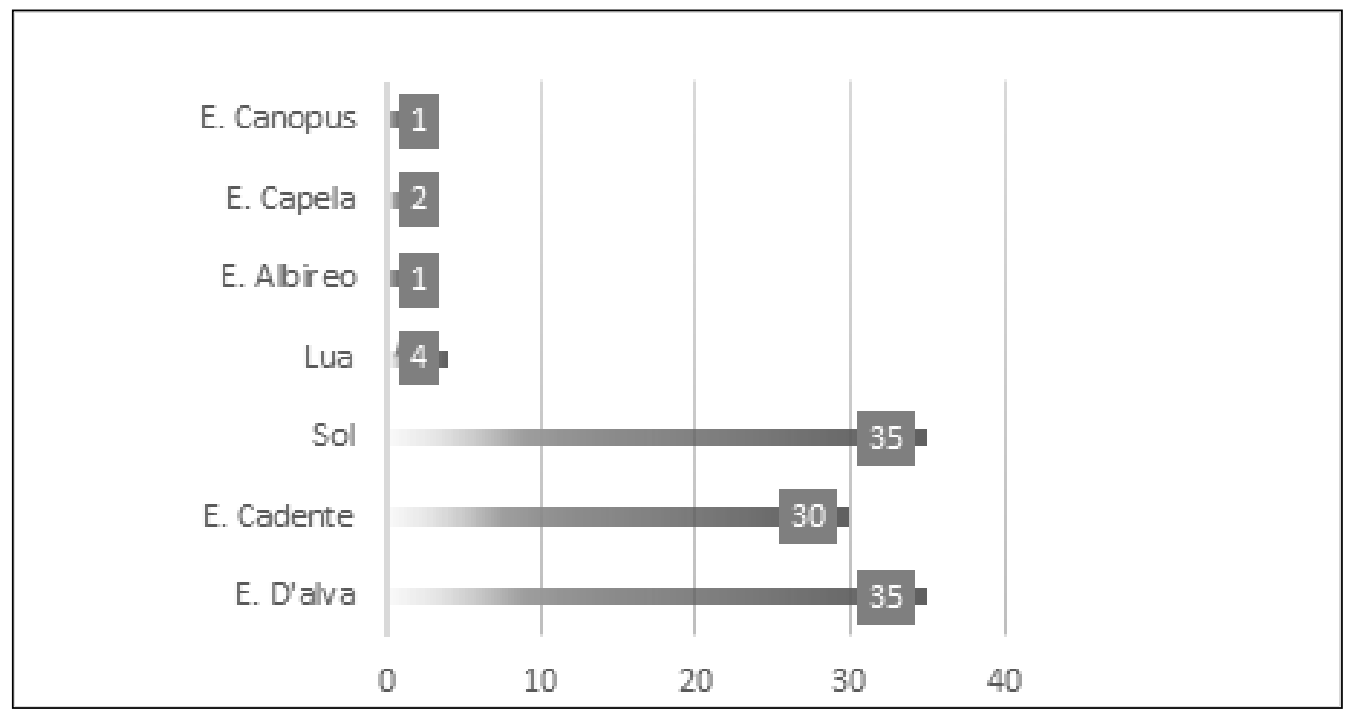

Fonte: dados da pesquisa (2019).

Dos 35 entrevistados, as principais estrelas conhecidas são: Estrela D'alva (35 participantes); Sol (35 participantes). A Estrela Cadente é conhecida por 35 participantes, sendo que a Lua foi citada por 4 entrevistados. As estrelas Canopus (1 citação), Capella (2 citações) e Albireo (1 citação) foram citadas por poucos. Cabe ressaltar que a Lua não é uma estrela e sim um satélite natural do Planeta Terra e as Estrelas Cadentes "são rochas espaciais, (fragmentos de asteroides e cometas), que ao entrar na atmosfera terrestre, em alta velocidade, acabam deixando um rastro luminoso no céu, provocado pelo atrito com os gases presentes na atmosfera" (MEDEIROS, 2007, p. 76).

A estrela Sirius, que é a de maior brilho de todo céu (BUENO, 2012), não foi citada pelos sujeitos da pesquisa. Outra informação importante é que a "Estrela D'alva" citada pelos entrevistados é, na verdade, o Planeta Vênus, muito conhecido por ser o corpo mais brilhante do céu e que é chamado de Estrela D'alva. As estrelas Canopus, Capella e Albireo (ou Beta Cygni) foram as menos citadas, sendo essas pertencentes às Constelações Quilha (ou Carina), Auriga e Cygnus, respectivamente.

Após a nomeação das estrelas que conheciam, os participantes foram questionados sobre qual o nome da maior estrela que conheciam? Dados representados no Quadro 2. 
Quadro 2: Nome da maior estrela conhecida pelos entrevistados

\begin{tabular}{|c|c|}
\hline Estrela & Total de citações \\
\hline Sol & 21 \\
\hline Dalva & 07 \\
\hline Cadente & 07 \\
\hline
\end{tabular}

Fonte: dados da pesquisa (2019).

Entre os 35 entrevistados, 21 deles citaram que a maior estrela para eles é o Sol, sendo a Estrela Cadente e a Dalva citadas por 7 participantes, cada uma. Assim, ao serem questionados sobre a maior estrela, evidenciase que o conhecimento para eles sobre o presente assunto se centra no Sol, demonstrando um conhecimento limitado sobre o tema em questão, pois a maior estrela do Universo é a $U$ Y Scuti, que é conhecida popularmente como supergigante vermelha, estando localizada na constelação de scutum e tem o seu raio mil e setecentos vezes maior que o do Sol, que é $700.000 \mathrm{~km}$ e 5000 anoluz distante da Terra (PIRES, 2018). No entanto, deve-se levar em consideração que as estrelas mais citadas pelos entrevistados são estrelas que se conseguem ver no Planeta Terra.

Em seguida, foram questionados sobre qual é, na concepção deles, a estrela mais próxima da Terra. Assim, 33 deles responderam ser o Sol a estrela mais próxima da Terra, sendo que 2 citaram a Lua, porém a Lua não é considerada uma estrela e sim um satélite do Planeta Terra.

Ao serem questionados sobre a utilização da Astronomia, no dia a dia, evidenciou-se que todos os integrantes da tribo, de certa forma, utilizam os conhecimentos empíricos que possuem sobre a Astronomia, como forma de orientação, plantio, entre outros costumes.

Ao responderem sobre a utilização dos seus conhecimentos de Astronomia, ou seja, em quais as tarefas do cotidiano que o ciclo lunar tem influência, responderam mais de uma atividade, sendo essa uma questão aberta e o resultado está representado conforme Figura 3. 
Figura 3: Tarefas do seu cotidiano influenciadas pelo ciclo lunar

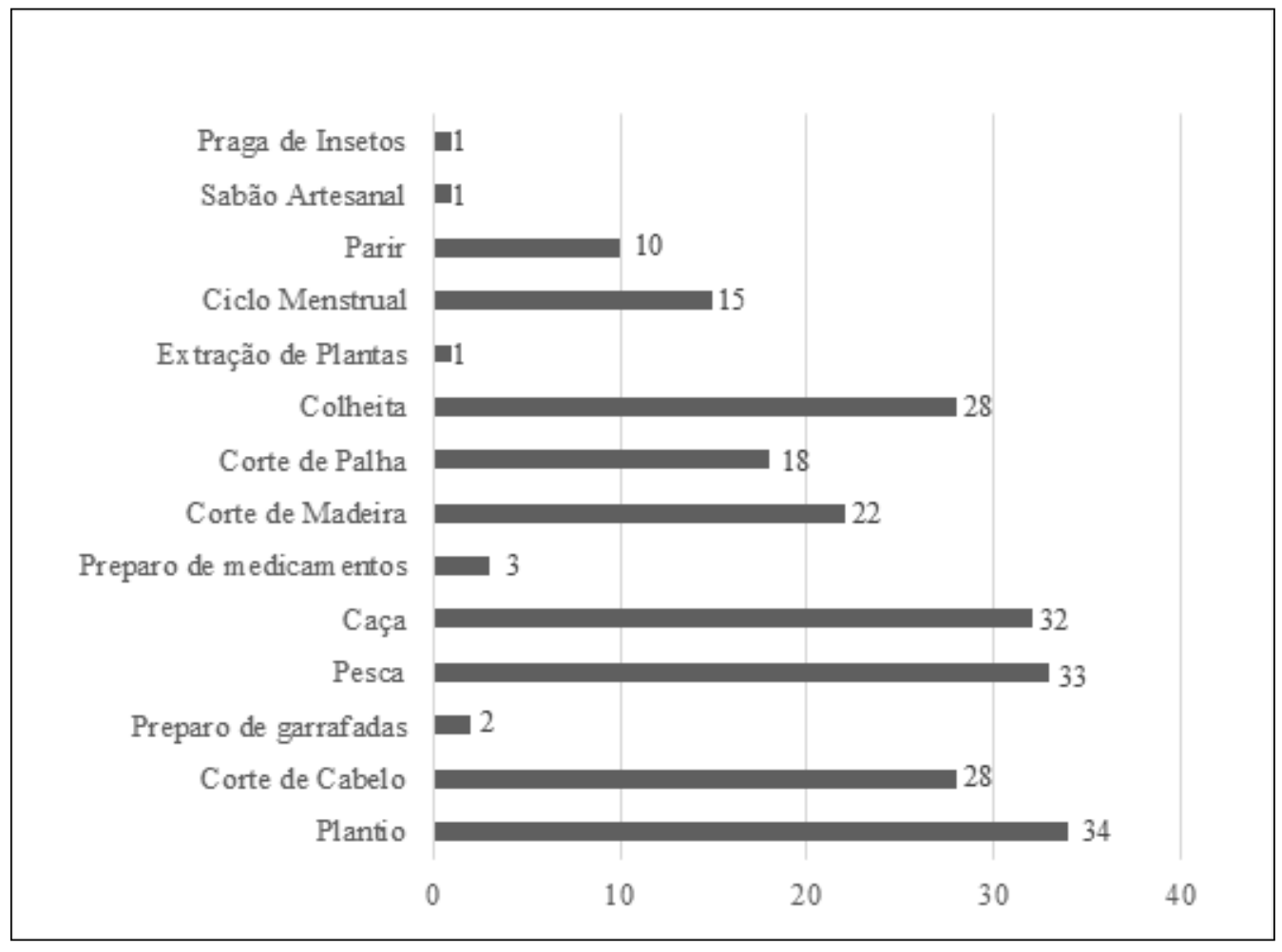

Fonte: dados da pesquisa (2019).

A Figura 3 apresenta as principais atividades relatadas pelos entrevistados sobre a influência lunar em suas vidas. A principal dessas é o plantio, sendo citado por 34 entrevistados. A pesca e a caça também estão entre as atividades mais citadas, por 33 e 32 entrevistados, respectivamente. Atividades como combate a pragas e insetos, extração de plantas e produção de sabão artesanal foram as menos citadas. As atividades mencionadas se aproximam das mesmas relatadas no estudo de Mariuzzo (2012).

Assim, questionou-se sobre como eles avaliam o próprio nível de conhecimento, relacionado com a Astronomia, 11 responderam que é "ótimo", 12 que têm um "bom" conhecimento e 11 afirmaram que têm conhecimento "regular" do assunto.

Portanto, ao se levantar a questão da influência do ciclo lunar no cotidiano dos integrantes da tribo Kanela do Araguaia, fica claro que estes a utilizam como fator próprio do dia a dia, em simples tarefas, como, por exemplo, plantio e colheita. O conhecimento sobre o ciclo lunar pela referida tribo traz consigo fatores que envolvem a raiz ancestral, em que o conhecimento acaba sendo passado de geração para geração, e deve ser seguido pela comunidade, 
de modo a possibilitar que o conhecimento permaneça por muitos anos na aldeia do mesmo modo que citado nos estudos de Afonso (2010) e Amorim e Paladino (2012).

Os conhecimentos, mesmo que empíricos, de Astronomia representam para a comunidade Kanela do Araguaia um fator importante para a sobrevivência de seus membros, pois por meio dos seus conhecimentos em tal matéria, é possível um direcionamento para o que se deverá realizar.

\section{CONSIDERAÇÕES FINAIS}

Com o presente estudo foi possível entender quais conhecimentos empíricos sobre Astronomia são utilizados no cotidiano da comunidade indígena Kanela do Araguaia, além de compreender a importância das fases lunares no cotidiano da comunidade indígena. Essa comunidade traz consigo uma cultura viva, que é passada de geração a geração, entre pais e filhos, de modo a materializar um conhecimento de décadas, que influencia a vida de todos.

A comunidade indígena busca utilizar a Astronomia como meio para se orientar e guiar em tarefas simples, corriqueiras, que vão desde o preparo de um medicamento até a colheita de produtos, que são necessários para a sua subsistência. No entanto, a Astronomia para a comunidade indígena traz consigo uma conexão, em que o olhar para o céu traz a história de seus antepassados.

A pesquisa apresentada proporcionou, não apenas verificar os conhecimentos empíricos sobre Astronomia, mas a necessidade de se ampliar tal conhecimento para a sociedade, principalmente, por meio do ensino de Física. As respostas apresentadas pelos entrevistados da comunidade indígena Kanela do Araguaia demonstram que muitas atividades de seu cotidiano são guiadas pela Astronomia. Para eles, a orientação pelas estrelas possibilita guiar sua vida.

A maioria dos entrevistados respondeu que utiliza a Astronomia como meio de se guiar para a caça, a pesca e o plantio, bem como acredita que observar as fases da Lua possibilita saber quando a mulher grávida irá dar à luz. Para a comunidade, o conhecimento de estrelas é, praticamente, igual para todos, em que a estrela mais conhecida é a Estrela Dalva.

Na percepção deles, o conhecimento que possuem sobre Astronomia é bom e regular, com exceção dos indígenas com mais idade, que afirmaram ter um conhecimento astronômico ótimo. Assim, o conhecimento apresentado pela comunidade indígena Kanela do Araguaia é um exemplo de que os conhecimentos das comunidades indígenas são importantes para eles e precisam ser divulgados e preservados. Estudos com etnias indígenas são importantes para se registrar a memória desses grupos e compreender quais conhecimentos e, de que forma, esses grupos mantêm os conhecimentos por 
gerações, que novos estudos possam investigar mais sobre os conhecimentos culturais e empíricos dos povos indígenas.

\section{REFERÊNCIAS}

ARAUJO, Diones Charles Costa de; VERDEAUX, Maria de Fátima da Silva; CARDOSO, Walmir Thomazi. Uma proposta para a inclusão de tópicos de astronomia indígena brasileira nas aulas de Física do Ensino Médio. Ciência \& Educação. v. 23, n. 4, p. 1035-1054, dez. 2017. Disponível em: <http:/ / www.scielo.br/scielo. php?script=sci_arttext\&pid=S1516-73132017000401035\&lng=pt\&nrm=iso $>$. Acesso em out. 2019.

AFONSO, Germano Bruno. Mitos e Estações no Céu Tupi-Guarani. Scientific American Brasil (Edição Especial: Etnoastronomia), v. 14, p. 46-55, 2006. disponível em: <https://www.mat.uc.pt/mpt2013/files/tupi_guarani_GA.pdf $>$. Acesso em: março 2019.

AFONSO, Germano Bruno. Astronomia Indígena: Conhecimento dos indígenas da família tupi-guarani antecipou teorias do século XVII. 2010. Disponível em: <http:/ / www.pindorama.art.br/file/17046historiaguarani.pdf>. Acesso em: maio 2019.

AFONSO, Germano Bruno. As constelações indígenas brasileiras. Telescópios na Escola, Rio de Janeiro, 2013. Disponível em: <http:/ / pindorama.art.br/file/ constelacoesindigenasguarani.pdf $>$. Acesso em: maio 2021.

AMORIM, Claudia; PALADINO, Mariana. Cultura e literatura africana e indígena. Curitiba: IESDE Brasil, 2012.

BRASIL. Presidência da República. Casa Civil. Constituição (2004). Decreto n ${ }^{\circ}$ 5.051, de 19 de abril de 2004. Convenção no 169 da OIT Sobre Povos Indígenas e Tribais. Brasília, DF, 19 de abril de 2004.

BRASIL. Base Nacional Comum Curricular (BNCC). Ministério da Educação. Homologação 14 de dezembro de 2018. Disponível em: <http:/ /basenacionalcomum. mec.gov.br/images/BNCC_EI_EF_110518_versao final_site.pdf $>$. Acesso em out. 2019.

BUENO, Loril Leocádio. Astronomia: observando o céu de maio. Arq. Apadec, 3(l) jan-jun., 2012. Disponível em: <https:/ / periodicos.uem.br/ojs/index.php/ArqMudi/ article/view/16786/9021>. acesso em: maio 2021.

CHIZZOTI, Antonio. Pesquisa qualitativa em Ciências Humanas e Sociais. Petrópolis-RJ: Editora Vozes, 2006.

GARCIA, Caroline da Silva; COSTA, Samuel; PASCOALI, Suzy, CAMPOS, Mateus Zanette. "As coisas do céu": Etnoastronomia de uma comunidade indígena como subsídio para a proposta de um material didático. Revista Latino-Americana de 
Educação em Astronomia - RELEA, n. 21, p. 7-30, 2016. Disponível em: <https:/ / www.relea.ufscar.br/index.php/relea/article/view/231/321>. Acesso em: maio 2021.

HOSOUME, Yassuko; LEITE, Cristina; CARLO, Sandra Del. Ensino de astronomia no Brasil - 1850 a 1951 - Um olhar pelo Colégio Pedro II. Ens. Pesqui. Educ. Ciênc. v. 12, n. 2, p. 189-204, ago. 2010. Disponível em: <http:/ /www.scielo.br/scielo. php?script=sci_arttext\&pid=S1983-21172010000200189\&lng=pt\&nrm=iso $>$. Acesso em: out. 2019.

LAGO, Leonardo; ORTEGA, José Luis; MATTOS, Cristiano. A lua na mão: mediação e conceitos complexos no ensino de astronomia. Ens. Pesqui. Educ. Ciênc. v. 20, 2018. Disponível em <http:/ / www.scielo.br/scielo.php?script=sci_arttext\&pid=S198321172018000100218\&lng=pt\&nrm=iso >. Acesso em: out. 2019.

LANGHI, Rodolfo. NARDI, Roberto. Ensino da astronomia no Brasil: educação formal, informal, não formal e divulgação científica. Revista Brasileira de Ensino de Física. v. 31, n. 4, 4402, 2009. Disponível em: <http:/ / www.scielo.br/pdf/rbef/ v31n4/v31n4a14>. Acesso em: 27 mai. 2019.

MARIUZZO, Patrícia. O céu como guia de conhecimentos e rituais indígenas.

Ciência e Cultura, São Paulo, v. 64, n. 4, p. 61-63, dez. 2012. Disponível em: $<$ http:/ / cienciaecultura.bvs.br/scielo.php?script=sci_arttext\&pid=S000967252012000400023\&lng=en\&nrm=iso >. Acesso em: mai. 2021.

MEDEIROS, José Renan de. Pedras Celestes, Lagrimas de Estrelas... Carcaças dos céus. Revista USP, São Paulo, p. 74-79, fev. 2007. Disponível em: <https:/ / www.revistas. usp.br/revusp/article/download/13570/15388>. Acesso em: jun. 2021.

NORA, Giseli Dalla Nora; ROSSETO, Onélia Carmem; SANTIAGO, Gabriella Matos; LIMA, Diogo Marcelo Delben Ferreira de. A Conflitualidade Da Questão Agrária Brasileira: Leituras a partir dos dados do Projeto Dataluta - Estado De Mato Grosso - Brasil. In: Del Bel, Haya; Caetano, Edson; Daniel Fanta. (Orgs.) Defesa da reforma agrária no Brasil: Primeira Jornada Universitária (JURA) no Mato Grosso. Uberlândia: Navegando Publicações, 2020.

PIRES, Antonio Sergio Teixeira. Onde estão os ETs? Um estudo sobre a possibilidade de vida no Universo. Timburi: Cia do Ebook, 2018.

SANZOVO, Daniel Trevisan; BALESTRA, Jayne Mateus. A Astronomia presente no ensino de Ciências numa sala de aula. Revista Educação Pública. v. 19, nº 17, ago. 2019. Disponível em: <https:/ / educacaopublica.cecierj.edu.br/artigos/19/17/aastronomia-presente-no-ensino-de-ciencias-numa-sala-de-aula $>$. Acesso em: mar. 2021. 